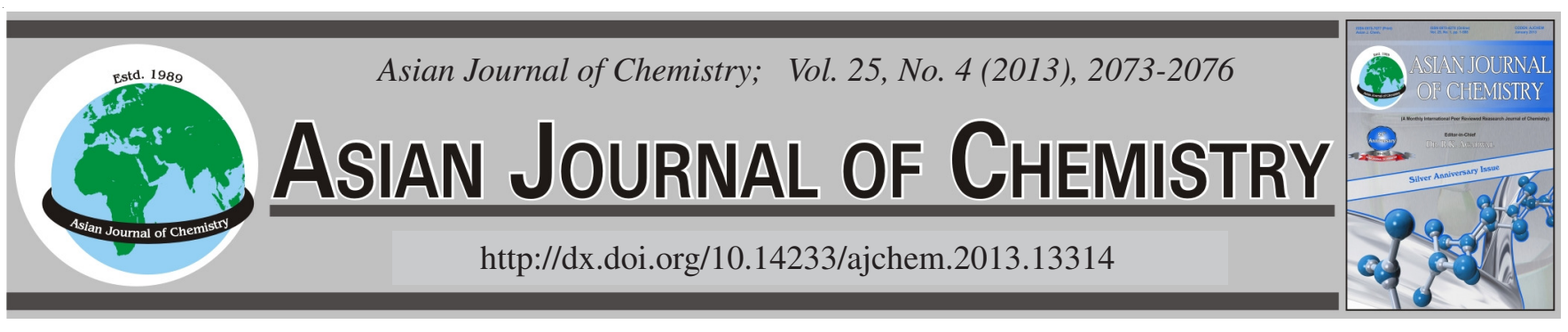

\title{
Application of Response Surface Methodology to Optimize the Extracting Process of Molybdenum from Nickel Molybdenum Ore
}

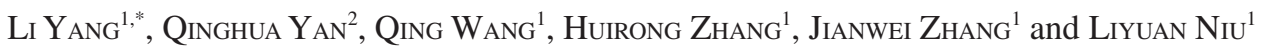

\begin{abstract}
${ }^{1}$ Department of Experimental Center, Henan Institute of Science and Technology, Xinxiang 453003, Henan Province, P.R. China
\end{abstract} ${ }^{2}$ Department of Life Science and Technology, Xinxiang Medical University, Xinxiang 453003, Henan Province, P.R. China

*Corresponding author: Fax: +86 373 3040015; Tel: +86 373 3040746; E-mail: manyouhome1998@yahoo.cn

The extraction of molybdenum was researched in order to find the effective recovery process. Through response surface methodology, the optimum condition was determined as follows: roasting temperature, $670{ }^{\circ} \mathrm{C}$; roasting time, $1.70 \mathrm{~h} ; \mathrm{NaOH}$ concentration, $60 \%$; liquid solid radio, 2. The yield of molybdenum was as high as $3.82 \%$.

Key Words: Molybdenum, Extraction, Response surface methodology.

\section{INTRODUCTION}

Molybdenum is a valuable alloying agent, as it contributes the hardness and toughness of quenched and tempered steels. It also improves the strength of steel at high temperatures. Molybdenum is used in alloys, electrodes and catalysts. The versatility of molybdenum in enhancing a variety of alloy properties has ensured it a significant role in contemporary industrial technology, which increasingly requires materials that are serviceable under high stress, expanded temperature ranges and highly corrosive environments. Moreover, molybdenum finds significant use as a refractory metal in numerous chemical applications, including catalysts, lubricants and pigments.

Nickel molybdenum ore is metal composite ores containing a variety of metallic and nonmetallic elements in China. The content of nickel is $0.17-7.03 \%$ and molybdenum is 0.35 $8.17 \%$. The chief source of molybdenum now is refined by molybdenite $\left(\mathrm{MoS}_{2}\right)$, which is the most valuable by-product of nickel molybdenum mining production. Many technical efforts have been developed in order to separate both metals by efficient methods ${ }^{1-3}$. Normally molybdenite concentrate is obtained by a selective flotation. Some of them are related to transport mechanism and permeability equations through membrane and others are concerned on practical applications of liquid membranes in diverse potential fields such as organic acid extraction, analysis of substances, nuclear waste processing, desalination of sea water and others. Usually the processing continues by roasting the sulphide concentrate to molybdenum trioxide in a step ${ }^{4-7}$, which is highly demanding of energy and environmentally objectionable due to the production of sulphur oxides. Then, leaching of molybdenite concentrates and recovery of dissolved metals by solvent extraction, which has become very important as a promising industrial process for the recovery of molybdenum from all kinds of molybdenum ores.

In a preliminary study, optimization could be used to maximize the extraction of molybdenum (molybdenum yield). Roasting temperature, roasting time, $\mathrm{NaOH}$ concentration and liquid to solid ratio were found to influence significantly the extraction of molybdenum. Response surface methodology is an effective tool for optimizing the process. Response surface methodology uses an experimental design such as the central composite design to fit a model by least squares technique. If the proposed model is adequate, as revealed by the diagnostic checking provide by an analysis of variance (ANOVA) and residual plots, contour plots can be usefully employed to study the response surface and located the optimum ${ }^{8}$. The purpose of current work was to optimize the yield of molybdenum in the nickel molybdenum ore by response surface methodology.

\section{EXPERIMENTAL}

The nickel molybdenum ore for this study was obtained from Luanchuan (Henan, PR China). $\mathrm{NaOH}$ and $\mathrm{HNO}_{3}$ of analytical grade were used as received.

Experimental processing: Nickel molybdenum ore was crushed in a mill and separated by sieving different sizes. 
Firstly, the powders were placed in muffle furnace (Shanghai Jinghong laboratory instrument Co. Ltd.) roasted at different temperature for different times. Then, the roasted products reacted with sodium hydroxide solution of different concentrations at $95^{\circ} \mathrm{C}$ for $2 \mathrm{~h}$ according to response surface methodology. Finally, after filtering the reaction products, the filtered solution was transferred into a volumetric flask and made up to $25 \mathrm{~mL}$ with $2 \% \mathrm{HNO}_{3}$. The concentration of molybdenum was detected by an inductively coupled plasma-atomic emission spectrometer (ICP-AES, Optima 2100 DV, Perkin Elmer, USA).

Response surface methodology design: One response was measured: the yield of molybdenum (Y), defined as the ratio of total molybdenum in the extract to total amount of molybdenum expressed as percentage. Each of variables to be optimized was coded at 5 levels: $-2,-1,0,1$ and 2 . Table- 1 shows the variables, their symbols and levels. The selection of variable levels was based on our preliminary study.

\begin{tabular}{|c|c|c|c|c|c|c|}
\hline \multicolumn{7}{|c|}{$\begin{array}{c}\text { TABLE- } 1 \\
\text { VARIABLES AND THEIR LEVELS FOR } \\
\text { CENTRAL COMPOSITE DESIGN }\end{array}$} \\
\hline \multirow{2}{*}{ Variable } & \multirow{2}{*}{ Symbol } & \multicolumn{5}{|c|}{ Code-variable level } \\
\hline & & -2 & -1 & 0 & 1 & 2 \\
\hline Roasting temperature $\left({ }^{\circ} \mathrm{C}\right)$ & $\mathrm{X}_{1}$ & 300 & 400 & 500 & 600 & 700 \\
\hline Roasting time (h) & $\mathrm{X}_{2}$ & 1.5 & 2.5 & 3.5 & 4.5 & 5.5 \\
\hline $\mathrm{NaOH}$ concentration $\left(\mathrm{g} \mathrm{mL}^{-1}\right)$ & $\mathrm{X}_{3}$ & 20 & 30 & 40 & 50 & 60 \\
\hline Liquid solid ratio & $\mathrm{X}_{4}$ & $5: 1$ & $4: 1$ & $3: 1$ & $2: 1$ & $1: 1$ \\
\hline
\end{tabular}

A central composite design, shown in Table-2, was arranged to allow for fitting of a second-order model. The central composite design combined the vertices of a hypercube whose coordinates are given by the $2^{\mathrm{n}}$ factorial design with the star points. The star points were added to the factorial design to provide for estimation of curvature of the model. Six replicates (run 25, 26, 27, 28, 29 and 30) at the center of the design were used to allow for estimation of pure error sum of squares. Experiments were randomized in order to minimize the effects of unexplained variability in the observed response due to extraneous factors.

Statistic analysis: A software package (design expert 7.0) was used to fit the second-order models and generate response surface plots. The model proposed for the response (Y) was:

$$
\mathrm{Y}=\mathrm{b}_{0}+\sum_{\mathrm{n}=1}^{4} \mathrm{~b}_{\mathrm{n}} \mathrm{x}_{\mathrm{n}}+\sum_{\mathrm{n}=1}^{4} \mathrm{~b}_{\mathrm{nn}} \mathrm{x}_{\mathrm{n}}^{2}+\sum_{\mathrm{n} \neq \mathrm{m}-1}^{4} \mathrm{~b}_{\mathrm{tm}} \mathrm{x}_{\mathrm{n}} \mathrm{x}_{\mathrm{m}}
$$

where, $b_{0}$ is the value of the fitted response at the center point of the design, which is point $(0,0,0,0) . \mathrm{B}_{\mathrm{n}}, \mathrm{b}_{\mathrm{nn}}$ and $\mathrm{b}_{\mathrm{nm}}$ are the linear, quadratic and cross-product regression terms, respectively.

\section{RESULTS AND DISCUSSION}

Diagnostic checking of the fitted model: ANOVA for the regression was performed to assess the goodness of fit. The model for $\mathrm{Y}$ was:

$\mathrm{Y}_{2}=1.67-0.29 \mathrm{X}_{1}-0.028 \mathrm{X}_{2}+0.009157 \mathrm{X}_{3}+0.016 \mathrm{X}_{4}-0.013 \mathrm{X}_{1} \mathrm{X}_{2}$ $+0.13 \mathrm{X}_{1} \mathrm{X}_{3}+0.008155 \mathrm{X}_{1} \mathrm{X}_{4}-0.051 \mathrm{X}_{2} \mathrm{X}_{3}+0.008875 \mathrm{X}_{2} \mathrm{X}_{4}-$

$0.041 \mathrm{X}_{3} \mathrm{X}_{4}-0.16 \mathrm{X}_{1}^{2}-0.030 \mathrm{X}_{2}^{2}-0.083 \mathrm{X}_{3}^{2}-0.045 \mathrm{X}_{4}^{2}$

where, $X_{1}$ means roasting temperature, $X_{2}$ is roasting time, $X_{3}$ is $\mathrm{NaOH}$ concentration, $\mathrm{X}_{4}$ is liquid-solid ratio. The coefficient of absolute value in equation reflects the size of the various factors on the extraction rate, positive and negative value of the reflection coefficient reflects the direction on the effect of extraction. It could be seen that calcination temperature, the interaction item of calcination temperature and the $\mathrm{NaOH}$ concentration, the square of roasting temperature were great influence the extraction of molybdenum.

\begin{tabular}{|c|c|c|c|c|c|}
\hline \multirow{3}{*}{ Run } & \multicolumn{4}{|c|}{$\begin{array}{c}\text { TABLE- } 2 \\
\text { CENTRAL COMPOSITE DESIGN } \\
\text { ARRANGEMENT AND REPONSE }\end{array}$} & \multirow{3}{*}{$\begin{array}{c}\text { Response } \\
\mathrm{Y}\end{array}$} \\
\hline & \multicolumn{4}{|c|}{ Variable level } & \\
\hline & $\mathrm{X}_{1}$ & $\mathrm{X}_{2}$ & $\mathrm{X}_{3}$ & $\mathrm{X}_{4}$ & \\
\hline 1 & 400.00 & 2.50 & 30.00 & 2.00 & 0.8805 \\
\hline 2 & 600.00 & 2.50 & 30.00 & 2.00 & 1.9956 \\
\hline 3 & 400.00 & 4.50 & 30.00 & 2.00 & 1.302 \\
\hline 4 & 600.00 & 4.50 & 30.00 & 2.00 & 3.8465 \\
\hline 5 & 400.00 & 2.50 & 50.00 & 2.00 & 1.0307 \\
\hline 6 & 600.00 & 2.50 & 50.00 & 2.00 & 2.9873 \\
\hline 7 & 400.00 & 4.50 & 50.00 & 2.00 & 1.4346 \\
\hline 8 & 600.00 & 4.50 & 50.00 & 2.00 & 2.7015 \\
\hline 9 & 400.00 & 2.50 & 30.00 & 4.00 & 1.6044 \\
\hline 10 & 600.00 & 2.50 & 30.00 & 4.00 & 2.7775 \\
\hline 11 & 400.00 & 4.50 & 30.00 & 4.00 & 0.0865 \\
\hline 12 & 600.00 & 4.50 & 30.00 & 4.00 & 3.5879 \\
\hline 13 & 400.00 & 2.50 & 50.00 & 4.00 & 0.8463 \\
\hline 14 & 600.00 & 2.50 & 50.00 & 4.00 & 2.8282 \\
\hline 15 & 400.00 & 4.50 & 50.00 & 4.00 & 0.3816 \\
\hline 16 & 600.00 & 4.50 & 50.00 & 4.00 & 2.3795 \\
\hline 17 & 300.00 & 3.50 & 40.00 & 3.00 & 3.6546 \\
\hline 18 & 700.00 & 3.50 & 40.00 & 3.00 & 1.7524 \\
\hline 19 & 500.00 & 1.50 & 40.00 & 3.00 & 1.7524 \\
\hline 20 & 500.00 & 5.50 & 40.00 & 3.00 & 1.8553 \\
\hline 21 & 500.00 & 3.50 & 20.00 & 3.00 & 2.1028 \\
\hline 22 & 500.00 & 3.50 & 60.00 & 3.00 & 2.0098 \\
\hline 23 & 500.00 & 3.50 & 40.00 & 1.00 & 2.8649 \\
\hline 24 & 500.00 & 3.50 & 40.00 & 5.00 & 2.2606 \\
\hline 25 & 500.00 & 3.50 & 40.00 & 3.00 & 2.2606 \\
\hline 26 & 500.00 & 3.50 & 40.00 & 3.00 & 2.4759 \\
\hline 27 & 500.00 & 3.50 & 40.00 & 3.00 & 3.2207 \\
\hline 28 & 500.00 & 3.50 & 40.00 & 3.00 & 3.4399 \\
\hline 29 & 500.00 & 3.50 & 40.00 & 3.00 & 2.6938 \\
\hline 30 & 500.00 & 3.50 & 40.00 & 3.00 & 2.8161 \\
\hline
\end{tabular}

Yield of molybdenum: The result of ANOVA was shown in Table-3. Values of Prob > F less than 0.05 indicated model terms were significant. Adeq Precision measures the signal to noise ratio. A ratio greater than 4 is desirable. The ratio of 6.328 indicated an adequate signal. This model could be used to navigate the design space.

Response surface plotting: Variables giving quadratic and interaction terms with the largest absolute coefficients in the fitted models were chosen for the axes of contour plots to account for curvature of the surfaces.

In Fig. 1, the effect of roasting temperature and $\mathrm{NaOH}$ concentration on the extraction of molybdenum at 3 liquid-solid ratio and $500^{\circ} \mathrm{C}$ is shown. The incease in $\mathrm{NaOH}$ concentration enabled higher alkalinity increase for oxidation reactions resulting in enhanced the yield of molybdenum within $2 \mathrm{~h}$. Above $2 \mathrm{~h}$ roasting temperature and between 30 and $50 \% \mathrm{NaOH}$ concentration, a region of more than $1 \%$ molybdenum yield was obtained. Maximum $3.84 \%$ of molybdenum yield obtained at $3.5 \mathrm{~h}$ roasting temperature and $40 \% \mathrm{NaOH}$ concentration. 


\begin{tabular}{cccccc}
\hline \multicolumn{5}{c}{ TABLE-3 } \\
\multicolumn{5}{c}{ ANOVA FOR THE FITTED MODEL } \\
\hline Source & $\begin{array}{c}\text { Sum of } \\
\text { squares }\end{array}$ & $\mathrm{d}_{\mathrm{f}}$ & $\begin{array}{c}\text { Mean } \\
\text { square }\end{array}$ & $\begin{array}{c}\mathrm{F} \\
\text { value }\end{array}$ & Prob $>$ F \\
\hline $\mathrm{X}_{1}$ & 1.98 & 1 & 1.98 & 23.36 & 0.0002 \\
$\mathrm{X}_{2}$ & 0.018 & 1 & 0.018 & 0.22 & 0.6478 \\
$\mathrm{X}_{3}$ & 0.002 & 1 & 0.002 & 0.024 & 0.8795 \\
$\mathrm{X}_{4}$ & 0.006 & 1 & 0.006 & 0.071 & 0.7928 \\
$\mathrm{X}_{1} \mathrm{X}_{2}$ & 0.002 & 1 & 0.002 & 0.033 & 0.8588 \\
$\mathrm{X}_{1} \mathrm{X}_{3}$ & 0.25 & 1 & 0.25 & 2.97 & 0.1055 \\
$\mathrm{X}_{1} \mathrm{X}_{4}$ & 0.001 & 1 & 0.001 & 0.013 & 0.9122 \\
$\mathrm{X}_{2} \mathrm{X}_{3}$ & 0.042 & 1 & 0.042 & 0.49 & 0.4929 \\
$\mathrm{X}_{3} \mathrm{X}_{4}$ & 0.027 & 1 & 0.027 & 0.32 & 0.5794 \\
$\mathrm{X}_{1}{ }^{2}$ & 0.74 & 1 & 0.74 & 8.73 & 0.0099 \\
$\mathrm{X}_{2}{ }^{2}$ & 0.024 & 1 & 0.024 & 0.29 & 0.6011 \\
$\mathrm{X}_{3}{ }^{2}$ & 0.19 & 1 & 0.19 & 2.21 & 0.1578 \\
$\mathrm{X}_{4}{ }^{2}$ & 0.056 & 1 & 0.056 & 0.67 & 0.4273 \\
Residual & 1.27 & 15 & 0.085 & & \\
Cor Total & 4.44 & 29 & & & \\
\hline
\end{tabular}

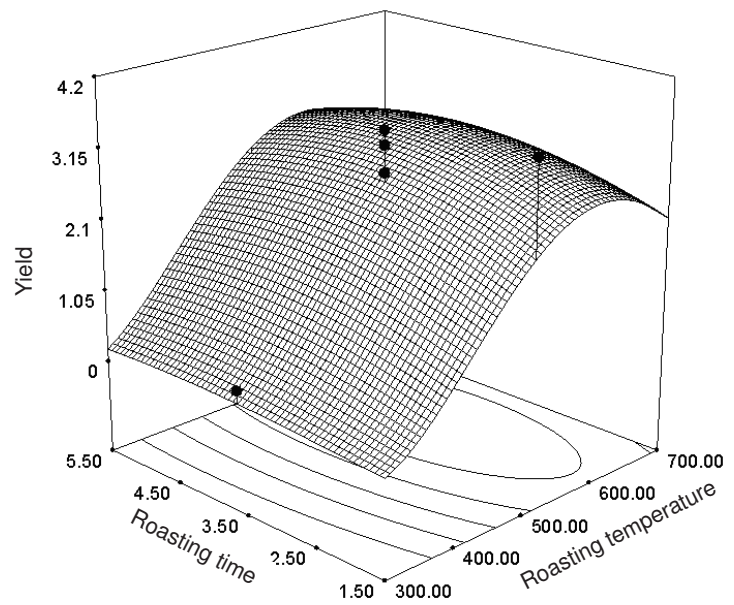

Fig. 2. Effect of roasting time and roasting temperature on the yield of molybdenum ( $\mathrm{NaOH}$ concentration: $40 \%$; liquid-solid ratio: 3 )

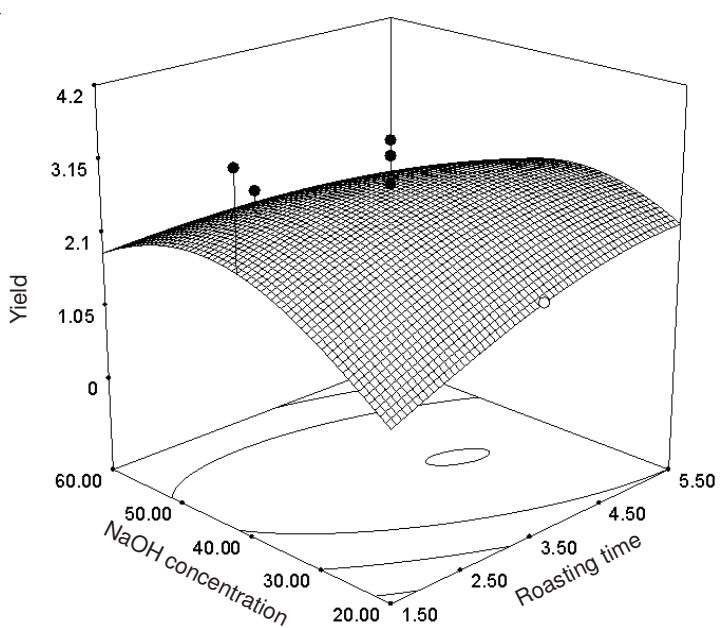

Fig. 1. Effect of $\mathrm{NaOH}$ concentration and roasting temperature on the yield of molybdenum (reaction temperature: $500{ }^{\circ} \mathrm{C}$; liquid-solid ratio: 3 )

Fig. 2 shows the change of the yield of molybdenum with roasting temperature and roasting time at 3 liquid-solid ratio and $40 \% \mathrm{NaOH}$ concentration. The increase in roasting temperature and roasting time both increased the yield of molybdenum. Maximum $3.86 \%$ of the yield of molybdenum was obtained at $500{ }^{\circ} \mathrm{C}$ reaction temperature and $3.5 \mathrm{~h}$. It could be seen the yield of molybdenum was almost constant with the increase in roasting temperature.

Fig. 3 shows the change of the yield of molybdenum with $\mathrm{NaOH}$ concentration and roasting temperature at 3 liquid-solid ratio and $3.5 \mathrm{~h}$ roasting time. The yield of molybdenum increased first and then decreased with the decrease in $\mathrm{NaOH}$ concentration and roasting temperature. A region of more than $3.83 \%$ the yield of molybdenum was achieved below $600{ }^{\circ} \mathrm{C}$ roasting temperature and $45 \% \mathrm{NaOH}$ concentration.

Fig. 4 shows the change of the yield of molybdenum with liquid-solid ratio and $\mathrm{NaOH}$ concentration at $500{ }^{\circ} \mathrm{C}$ roasting temperature and $3.5 \mathrm{~h}$ roasting time. The increase in liquidsolid ratio and $\mathrm{NaOH}$ concentration both increased the yield of molybdenum. Maximum $3.28 \%$ of the yield of molybdenum was obtained at 3 liquid-solid ratio and $40 \% \mathrm{NaOH}$ concentration. It could be seen the yield of molybdenum was almost constant with the increase in liquid-solid ratio.

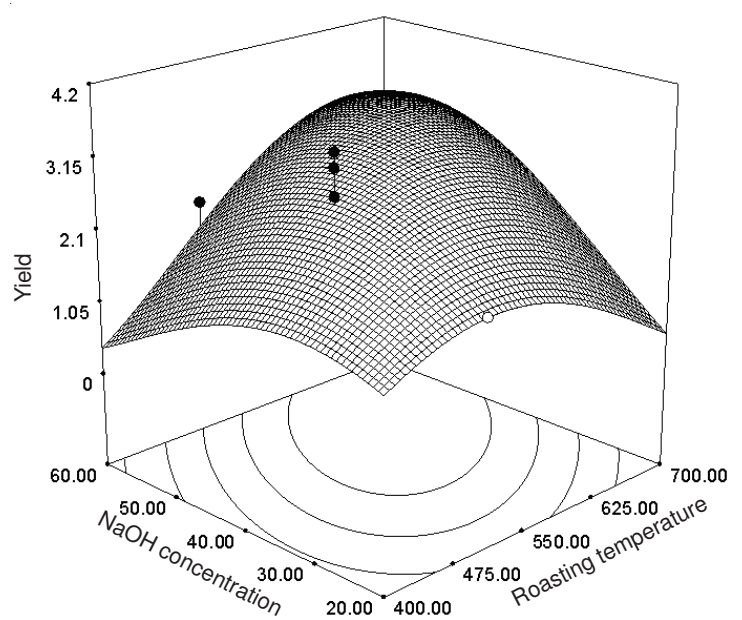

Fig. 3. Effect of $\mathrm{NaOH}$ concentration and roasting temperature on the yield of molybdenum (roasting time : $3.5 \mathrm{~h}$; liquid-solid ratio: 3 )

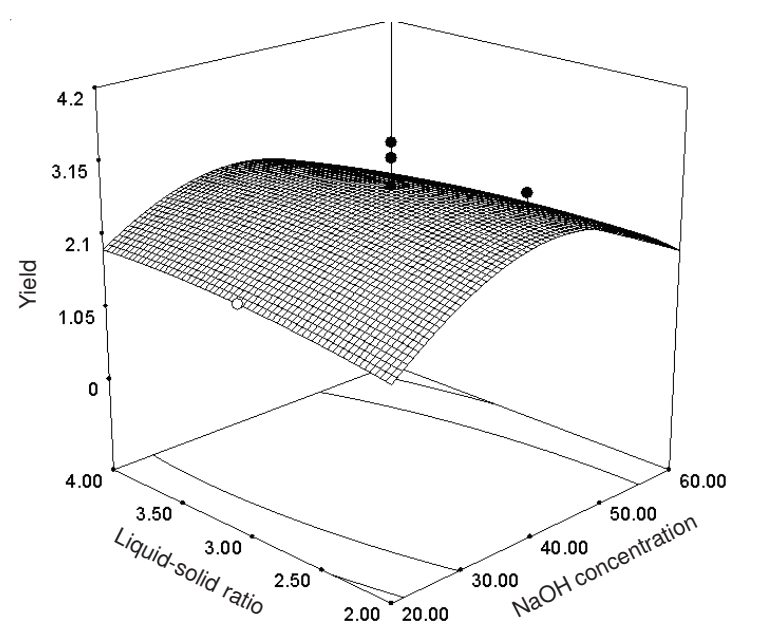

Fig. 4. Effect of liquid-solid ratio and $\mathrm{NaOH}$ concentration on the yield of molybdenum (roasting time : $3.5 \mathrm{~h}$; reaction temperature: $500{ }^{\circ} \mathrm{C}$ )

Optimization: The model is useful in indicating the direction in which to change variables in order to maximize the yield of molybdenum (Y). By using Design Expert 7.0 software, the point at roasting temperature $670{ }^{\circ} \mathrm{C}$, roasting time $1.70 \mathrm{~h}, \mathrm{NaOH}$ concentration $60 \%$ and 2 liquid-solid ratio could be recommended as a practical optimum. The estimated 
values for $\mathrm{Y}$ were $3.82 \%$. A verification experiment at the optimum condition, consisting of 3 runs, was performed and the practical Y was $3.82 \%$.

\section{Conclusion}

Optimum extraction of molybdenum from nickel molybdenum ore with $60 \% \mathrm{NaOH}$ extraction and $1.7 \mathrm{~h}$ roasting time at 2 liquid-solid ratio and $670{ }^{\circ} \mathrm{C}$ roasting temperature. Such conditions resulted in extraction of $3.82 \%$ molybdenum from nickel molybdenum ore.

\section{REFERENCES}

1. N. Tbeur, T. Rhlalou, M. Hlaibi, D. Langevin, M. Metayer and J.F. Verchere, Carbohyd. Res., 329, 409 (2000).

2. G.O. Yahaga, Sep. Sci. Technol., 36, 3563 (2001).

3. J. Trocewicz, J. Sep. Sci., 24, 587 (2001).

4. C. Basualto, J. Marchese, F. Valenzuela and A. Acosta, Talanta, 59, 999 (2003).

5. B.B. Kar, B.V.R. Murthy and V.N. Misra, J. Miner. Proc., 76, 143 (2005).

6. F.R. Valenzuela, J.P. Andrade, J. Sapag, C. Tapia and C. Basualto, Miner. Eng., 8, 893 (1995).

7. B.B. Kar, P. Datta and V.N. Misra, Hydrometallurgy, 72, 87 (2004).

8. Y.X. Ma, B.G. Liu, L.B. Hu and M.Y. Wang, Adv. Mater. Res., 343344, 933 (2011). 